\title{
Chromosomal substitution analysis of receptivity and sexual isolation in Drosophila melanogaster females
}

\author{
MARÍA C. CARRACEDO*, R. PIÑEIRO \& P. CASARES \\ Area de Genética, Departamento de Biología Funcional, Facultad de Medicina, 33071 Oviedo, Spain
}

\begin{abstract}
A chromosome substitution analysis was carried out in Drosophila melanogaster to elucidate the contribution of the X, II and III chromosomes to female receptivity, and to sexual isolation with its sibling species $D$. simulans. Two lines from the same base population with extreme phenotypes, the one showing high receptivity and weak isolation and the other showing low receptivity and strong isolation, were used. Genes involved in receptivity were located in chromosome III whereas those affecting sexual isolation were located in all the three chromosomes. These results indicate that the direct relationship between female receptivity and sexual isolation previously detected in $D$. melanogaster could be because of the occurrence of genes common to the two traits in the chromosome III.
\end{abstract}

Keywords: chromosomal analysis, Drosophila melanogaster, Drosophila simulans, female receptivity, sexual isolation.

\section{Introduction}

Drosphila melanogaster and $D$. simulans are sibling species with reproductive isolation based on ethological differences that make mating difficult, and on partial inviability and total sterility of their hybrid progenies. However, despite these premating and postmating isolation mechanisms, both species hybridize in nature and in the laboratory, mainly in the $D$. melanogaster female $\times D$. simulans male direction (Sturtevant, 1920, 1929; Manning, 1959; Sperlich, 1962; Carracedo \& Casares, 1985).

The determination of the genetic bases of characters involved in premating isolation mechanisms and the understanding of their evolution from homospecific behaviours are two basic aspects of speciation studies. In this respect, several studies have demonstrated that the break-up of sexual isolation in these species is influenced by the level of female receptivity in such a way that the faster females in homospecific mating are those that hybridize more frequently with $D$. simulans males (Carracedo et al., 1987, 1991). To examine the nature of this relationship in depth it is necessary to know if the correlation between hybridization and receptivity has a genetic component.

${ }^{*}$ Correspondence.
It has been shown that hybridization and female sexual receptivity have interpopulational and intrapopulational variation (Parsons, 1972; Watanabe et al., 1977; Carracedo \& Casares, 1985; Carracedo et al., 1991). Genes involved in hybridization appear to be polygenic with additive effects, as is shown by both the response to artificial selection (Eoff, 1975, 1977; Izquierdo et al., 1992) and the results of crosses between lines with high and low hybridization values (Carracedo et al., 1989). Female receptivity also has an important genetic determination characterized by additive genes and some dominance for high levels of expression, as has been found in a diallel study (Casares et al., 1992), and in a successful artificial selection programme (Piñeiro et al., 1993).

That the above correlation between female receptivity and hybridization is in part genetic has been demonstrated by Carracedo et al. (1991) in a populational study using isofemale lines. This genetic correlation can appear if: (i) both traits are pleiotropic effects of the same genetic system, and (ii) the genes underlying the two traits are located in the same chromosome and there is between them linkage disequilibrium maintained by selection (Lande, 1980; Falconer, 1989). To investigate these alternatives, it would be of great interest to know the number and location of genes affecting both traits. 
The chromosome substitution analysis allows the estimation of the relative effects of genes on each chromosome on a particular character (Mather, 1942; Mather \& Harrison, 1949; Robertson, 1954; Mather \& Jinks, 1982). It is often the first step in analysing the biological basis of Drosophila melanogaster phenotypes, mainly those involved in quantitative and/or behavioural traits (Kearsey \& Kojima, 1967; Mac Bean et al., 1971; Pyle, 1978; Sokolowski, 1980; Bauer \& Sokolowski, 1985; Ricker \& Hirsch, 1985, 1988; Fukui \& Gromko, 1991; Piñeiro, 1992; Ruiz-Dubreuil \& Köhler, 1994).

In this paper we report a chromosome substitution analysis from two $D$. melanogaster lines showing extreme phenotypes for receptivity and hybridization. Both lines came from the same base population and were achieved through independent artificial selection programmes.

\section{Materials and methods}

\section{Strains}

Selection lines were obtained from a $D$. melanogaster base population having 10 per cent hybridization frequency and a mean time to mating (the standard measure of receptivity) of $11 \mathrm{~min}$. Hybridization and receptivity were estimated as detailed below.

Selection for increasing hybridization between $D$. melanogaster females and $D$. simulans males was successful (Izquierdo et al., 1992) giving rise to a $D$. melanogaster line, called S, with 80 per cent hybridization. This line showed a receptivity mean time of $4 \mathrm{~min} 23 \mathrm{~s}$ at the end of the selection process.

Selection for decreasing homospecific receptivity was also succesful (Piñeiro et al., 1993) and the resulting $U$ line showed a receptivity mean time of $38 \mathrm{~min} 27 \mathrm{~s}$ and 2 per cent of hybridization frequency at the end of the selection.

The substitution lines were obtained using a $D$. melanogaster stock with the chromosome balancers Binscy (In(1) $\left.s c^{S I L} s c^{8 R}+\mathrm{dl} 49, y^{c 4} s c^{8} s c^{s 1} B\right)$, SM5 (In(2LR) SM5, $a l^{2} C y l t^{\nu} s n^{2} s p^{2}$ ) and TM3 (In(3LR) TM3, $y^{+} r i p^{p}$ sep $\left.S b b x^{34 e} e^{s}\right)$ in chromosomes X, II and III, respectively.

\section{Substitution lines}

Following the scheme used by Kearsey \& Kojima (1967), the cross of the $S$ and $U$ selection lines with the multiple inversion stock produced eight substitution lines, each with a different combination of the $X$, II and III chromosomes from the $S$ and $U$ lines (Fig. 1). The IV chromosome was ignored in this analysis.

Other specific lines are described in the corresponding tests.

\section{Receptivity test}

One virgin female from one chromosome substitution line and two tester males were aspirated into a

CROSS 1

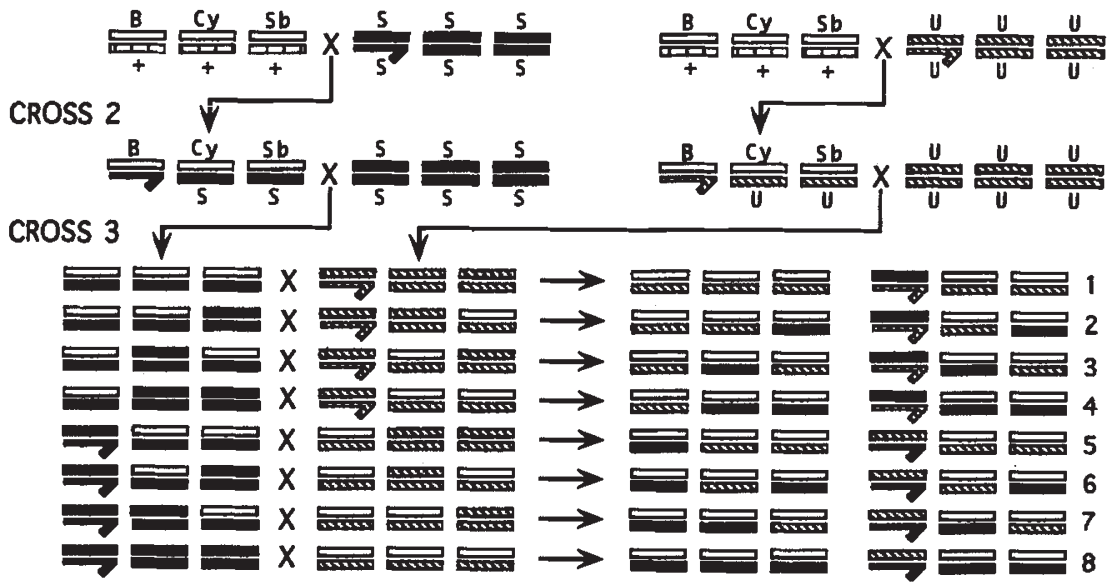

CROSS 4

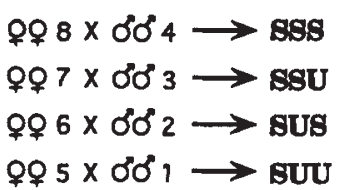

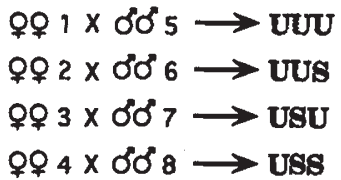

Fig. 1 Mating scheme employed to obtain eight chromosome substitution lines consisting of every possible homozygous combination of the X, II and III chromosomes between the lines selected for low female receptivity (U line) and for high female hybridization (S line). 
vial with food and the time to mating in seconds was registered as a measure of receptivity. All the individuals were 3 days old. The tester males came from a D. melanogaster iosfemale line, named M-33, that was also used in the selection process for female receptivity (Piñeiro et al., 1993). A total of 100 replicates for each chromosome substitution line were made.

Flies were observed for a maximum of $30 \mathrm{~m}$. The raw data (in seconds) were log-transformed to obtain a normal distribution (Dow, 1976). Because not all flies mated in the observation period, a procedure outlined by Manning (1961) was followed that permits the extrapolation of mean and variances from truncated data, that is, from the observed mating times only. The cumulative percentages of females mated during the test were transformed into probit values and plotted against the corresponding log-transformed mating times in seconds. This procedure gives a good straight-line plot from which we estimate the mean mating time (Piñeiro et al., 1993).

Measurements were performed in the morning in a $21^{\circ} \mathrm{C}$ thermoregulated room.

\section{Hybridization test}

Ten $D$. melanogaster females from one chromosome substitution line and $10 \mathrm{D}$. simulans males, all newly emerged, were placed in a vial with food. Males came from a line selected for increased hybridization success with $D$. melanogaster females (Izquierdo et al., 1992). Five days later, males were discarded and females transferred individually to fresh food vials. The presence of larvae in these vials was taken as evidence of hybridization. The measurement cri- terion provides the same results as dissection of mated females (M. C. Carracedo unpublished data). Three hundred females per chromosomal substitution line were tested in two sets of 150 females each.

\section{Results}

\section{Receptivity}

The means and standard errors of the log-transformed mating times are shown in Table 1 . The effect for each of the three chromosomes was evaluated by a $2 \times 2 \times 2$ factorial ANOVA (Table 2). Only chromosome III had a highly significant effect and none of the interactions among chromosomes was significant at the 0.05 level. In accordance with these results, genes involved in female receptivity are located in chromosome III.

\section{Hybridization}

The hybridization percentages of the two replicates, each based on 150 females, are shown in Table 1. The hybridization values of both replicates were compared by a test of paired data on the arcsine scale. No differences were detected $\left(t_{7}=0.015\right.$, $P=0.99$ ). The effect of each chromosome on hybridization was estimated from the data of the two replicates after transforming percentages to angles. The factorial ANOva (Table 2) shows significant effects of the three chromosomes and interactions between chromosomes X-III and II-III. These results indicate that the genes involved in female sexual isolation are located in all the major chromosomes, the $\mathrm{X}$ chromosome being the least important.

Table 1 Means and standard errors in log of seconds of the mating times (female receptivity) and percentages of hybridization found in each of two replicates $(N=150)$ and in the pooled data $(N=300)$, for each chromosome substitution line

\begin{tabular}{|c|c|c|c|c|}
\hline \multirow[b]{2}{*}{ Lines } & \multirow{2}{*}{$\frac{\text { Female receptivity }}{\text { Mean } \pm S E}$} & \multicolumn{3}{|c|}{ Hybridization } \\
\hline & & Replicate I & Replicate II & Pooled data \\
\hline SSS & $2.77 \pm 0.05$ & 77.33 & 72.00 & 74.66 \\
\hline SSU & $3.29 \pm 0.08$ & 74.66 & 70.66 & 72.66 \\
\hline SUS & $2.78 \pm 0.06$ & 64.00 & 64.00 & 64.00 \\
\hline SUU & $3.33 \pm 0.07$ & 10.00 & 12.66 & 11.33 \\
\hline USS & $2.78 \pm 0.04$ & 66.66 & 70.66 & 68.66 \\
\hline USU & $3.51 \pm 0.11$ & 52.00 & 47.33 & 49.66 \\
\hline UUS & $3.01 \pm 0.06$ & 51.33 & 51.33 & 51.33 \\
\hline UUU & $3.61 \pm 0.10$ & 5.33 & 4.00 & 4.66 \\
\hline
\end{tabular}


Table 2 Three-way factorial ANOvas of the mating times in log of seconds (female receptivity) and of the arcsin transformed percentages of hybridization

\begin{tabular}{|c|c|c|c|c|}
\hline \multirow[b]{2}{*}{ Source of variation } & \multicolumn{2}{|c|}{ Female receptivity } & \multicolumn{2}{|c|}{ Hybridization } \\
\hline & d.f. & MS & d.f. & MS \\
\hline$X$ & 1 & 0.80 & 1 & $212.57^{* * *}$ \\
\hline II & 1 & 0.01 & 1 & $2071.16^{* * *}$ \\
\hline III & 1 & $8.42^{* * *}$ & 1 & $1458.10^{* * *}$ \\
\hline $\mathrm{X} \times \mathrm{II}$ & 1 & 0.49 & 1 & 8.65 \\
\hline $\mathrm{X} \times \mathrm{III}$ & 1 & 0.20 & 1 & $39.49^{*}$ \\
\hline II $\times$ III & 1 & 0.13 & 1 & $660.87^{* * *}$ \\
\hline $\mathrm{X} \times \mathrm{II} \times \mathrm{III}$ & 1 & 0.00 & 1 & 12.58 \\
\hline Error & 792 & 0.26 & 8 & 4.52 \\
\hline
\end{tabular}

${ }^{*} P<0.05,{ }^{* * *} P<0.001$.

\section{Correlation}

The existence of a relation between female hybridization and receptivity is an important aspect on which this study is based. To estimate the correlation between the mean values of receptivity and hybridization we used a nonparametric test as substitution lines were not a random sample of genotypes. The Spearman rank test (Siegel \& Castellan, 1988) was significant $\left(r_{\mathrm{s}}=-0.83, P=0.028\right)$ indicating that the most receptive females (i.e. with shorter mating times) were those that hybridized more frequently. Thus, a clear and direct relationship between these two female behaviours was again found.

\section{Discussion}

The strength of our analysis is limited as we performed the chromosomal substitution from selected lines that belong to the same base population (Carracedo et al., 1991). Analyses from other populations or strains will be necessary to generalize our conclusions. However, some aspects about the genetic correlation between female hybridization and receptivity have been sufficiently clarified, mainly the demonstration of the existence of different genetic systems for both traits.

The analysis of chromosome substitution lines shows that large-effect genes for mating speed are located in chromosome III, whereas hybridization genes are in the three major chromosomes, the interaction between chromosomes II and III being very important. From these results it is clear that different genetic systems are involved in receptivity and sexual isolation, although the important correlation between both sexual traits found here and in other studies using different lines and populations (Carracedo et al., 1987, 1991) strongly suggests that genes in chromosome III could be common to the two characters. This should not be too surprising because males from $D$. melanogaster and $D$. simulans display quite similar courtship behaviours (Cowling \& Burnet, 1981; Cobb et al., 1985; Welbergen et al., 1987 ) and highly receptive $D$. melanogaster females mate with both types of males. In fact, it is supposed that females are faced with a compromise between two opposite aspects of the mating behaviour: sexual selection and conspecific recognition on one side and the need for species discrimination on the other. In this sense, low receptivity and high species discrimination is one of the ends in the female mating behaviour spectrum whereas high receptivity and low discrimination is the other end (Carracedo et al., 1987).

As mentioned in the Introduction, genes affecting sexual isolation between $D$. melanogaster and $D$. simulans seem to be mostly polygenic with additive effects and our results suggest that these genes have accumulated in autosomes more than in the $\mathrm{X}$ chromosome. A similar location of premating isolation genes in autosomes has been reported by Coyne $(1989,1992)$ in females of the simulans complex $(D$. simulans, $D$. sechellia and $D$. mauritiana). These data, together with our results, contrast strongly with Drosophila postmating isolation studies in which, as a rule, the involvement of the $\mathrm{X}$ chromosome is much greater than that of the autosomes; in fact, the different locations of pre- and postmating isolation genes are the expression of their different evolutionary pressures and patterns (Charlesworth et al., 1987; Coyne \& Orr, 1989; Orr, 1989; Orr \& Coyne, 1989; Coyne, 1991; Cabot et al., 1994). 


\section{Acknowledgements}

This work was supported by the Ministry of Education and Science of Spain (DGICYT Grant no. PB 92-1004).

\section{References}

BAUER, S. J. AND SOKOLOWSKI, M. в. 1985. A genetic analysis of path length and pupation height in a natural population of Drosophila melanogaster. Can. J. Genet. Cytol., 27, 334-340.

CABOT, E. L., DAVIS, A. W., JOHNSON, N. A. AND WU, CH. I. 1994. Genetics of reproduction isolation in the Drosophila simulans clade: complex epistasis underlying hybrid male sterility. Genetics, 137, 175-189.

CARRACEDO, M. C. AND CASARES, P. 1985. Intrapopulation genetic variation in the hybridization between Drosophila melanogaster and D. simulans males. Experienta, 41, 106-108.

CARRACEDO, M. C., CASARES, P. AND SAN MIGUeL, E. 1987. Sexual isolation between Drosophila melanogaster females and $D$. simulans males. II. Influence of female receptivity on hybridization. Genome, 29, 334-339.

CARRACEDO, M. C., CASARES, P., IZQUIERDO, J. AND PINEEIRO, R. 1991. Receptivity and sexual maturation of Drosophila melanogaster females in relation to hybridization with $D$. simulans males: a populational analysis. Anim. Behav., 42, 201-208.

CARRACEDO, M. C., GARCIA-FLOREZ, L. AND SAN MIGUEL, E. 1989. Sexual maturation in Drosophila melanogaster females and hybridization with $D$. simulans males: a study of inheritance modes. J. Hered., 80, 157-158.

CASARES, P., CARRACEDo, M. C., PIÑElRo, R. AND SAN MIGUEL, E. 1992. Genetic basis for female receptivity in Drosophila melanogaster: a diallel study. Heredity, 69, 400-411.

COBB, M., CONNOLLY, K. AND BURNET, в. 1985. Courtship behaviour in the melanogaster species sub-group of Drosophila. Behaviour, 95, 203-231.

COWLING, D. E. AND BURNET, в. 1981. Courtship songs and genetic conrol of their acoustic characteristics in sibling species of the Drosophila melanogaster subgroup. Anim. Behav., 29, 924-935.

COYNE, J. A. 1989. Genetics of sexual isolation between two sibling species, Drosophila simulans and D. mauritiana. Proc. Natl. Acad. Sci. U.S.A., 86, 5464-5468.

COYNE, J. A. 1991. Genetics and speciation. Nature, 355, 511-515.

COYNE, J. A. 1992. Genetics of sexual isolation in females of the Drosophila species complex. Genet. Res., 60, $25-31$.

COYNE, J. A. AND ORR, H. 1989. Patterns of speciation in Drosophila. Evolution, 43, 362-381.

CHARLESWORTH, B., COYNE, J. A. AND BARTON, N. H. 1987. The relative rates of evolution of sex chromosomes and autosomes. Am. Nat., 130, 113-146.

Dow, M. A. 1976. Analysis of truncated distributions: mat- ing speed in D. melanogaster. Behav. Genet., 6, 385-389.

EOFF, M. 1975. Artificial selection in Drosophila melanogaster females for increased and decreased sexual isolation from D. simulans males. Am. Nat., 109, 225-229.

EOFF, M. 1977. Artificial selection in D. simulans males for increased and decreased sexual isolation from $D$. melanogaster females. Am. Nat., 111, 259-266.

FALCONER, D. s. 1989. Introduction to Quantitative Genetics, 3rd edn. John Wiley, New York.

FUKUI, H. H. AND GROMKO, M. H. 1991. Genetic basis for remating in Drosophila melanogaster. IV. A chromosome substitution analysis. Behav. Genet., 21, 169-182.

IZQUIERDO, J. I., CARRACEDO, M. C., PIÑEIRO, R. AND CASARES, P. 1992. Response to selection for increased hybridization between Drosophila melanogaster females and D. simulans males. J. Hered., 83, 100-104.

KEARSEY, M. J. AND KOJIMA, K. 1967. The genetic architecture of body weight and egg hatchability in Drosophila melanogaster. Genetics, 56, 23-37.

LANDE, R. 1980. The genetic covariance between characters maintained by pleiotropic mutations. Genetics, 94 , 203-215.

MAC BEAN, I. T., McKENZIE, J. A. AND PARSONS, P. A. 1971. A pair of closely linked genes controlling high scutellar chaeta number in Drosophila. Theor. Appl. Genet., 41, 227-235.

MANNing, A. 1959. The sexual isolation between Drosophila melanogaster and D. simulans. Anim. Behav., 7, $60-65$.

MANNING, A. 1961. The effects of artificial selection for mating speed in Drosophila melanogaster. Anim. Behav., 9, 82-92.

MATHER, K. 1942. The balance of polygenic combinations. J. Genet., 43, 309-336.

MATHER, K. AND HARRISON, B. J. 1949. The manifold effects of selection. Heredity, 3, 1-52, 131-162.

MATHER, K. AND JINKs, J. L. 1982. Biometrical Genetics, 3rd edn. Chapman and Hall, New York.

ORR, H. A. 1989. Genetics of sterility in hybrids between two subspecies of Drosophila. Evolution, 43, 180-189.

ORR, H. A. AND COYNE, J. A. 1989. The genetics of postzygotic isolation in the Drosophila virilis group. Genetics, 121, 527-537.

PARSONS, P. A. 1972. Variations between strains of Drosophila melanogaster and $D$. simulans in giving offspring in interspecific crosses. Can. J. Genet. Cytol., 14, 77-80.

PIÑEIRO, R. 1992. Canalization at two extra scutellar bristles: artificial selection, chromosome anlaysis and effect of temperature. J. Hered., 83, 85-91.

PIÑEIRO, R., CARRACEDo, M. C., IZQUIERDO, J. I. AND CASARES, P. 1993. Bidirectional selection for female receptivity in Drosophila melanogaster. Behav. Genet., 23, $77-83$.

PYLE, D. w. 1978. A chromosome substitution analysis of geotactic maze behavior in Drosophila melanogaster. Behav. Genet., 8, 53-64.

RICKER, J. P. AND HIRSCH, J. 1985. Evolution of an instinct under long-term divergent selection for geotaxis in domesticated populations of Drosophila melanogaster. $J$. 
Comp. Psychol., 99, 380-390.

RICKER, J. P. AND HIRSCH, J. 1988. Reversal of genetic homeostasis in laboratory populations of Drosophila melanogaster under long-term selection for geotaxis and estimates of gene correlates: evolution of behaviourgenetic systems. J. Comp. Psychol., 102, 203-214.

ROBERTSON, F. W. 1954. Studies in quantitative inheritance. V. Chromosome analysis of crosses between selected and unselected lines of different body size in Drosophila melanogaster. J. Genet., 54, 494-520.

RUIZ-DUBREUIL, D. G. AND KÖHLER, N. 1994. Chromosomal analysis of gregarious oviposition by Drosophila melanogaster. Behav. Genet., 24, 187-190.

SIEGEL, S. AND CASTELLAN, N. J. 1988. Nonparametric Statistics for the Behavioral Sciences, 2nd edn. McGraw-Hill Book Company, New York.

SPERLICH, D. 1962. Hybrids between Drosophila melano- gaster and D. stimulans in nature. Dros. Inf. Serv., 36, 118.

soKolowsкı, м. в. 1980. Foraging strategies of Drosophila melanogaster: a chromosomal analysis. Behav. Genet., 10, 291-302.

SturteVant, A. H. 1920. Genetic studies on Drosophila simulans. I. Introduction. Hybrids with $D$. melanogaster. Genetics, 5, 488-500.

StURTEVANT, A. H. 1929. The genetics of Drosophila simulans. Carnegie Inst. Wash. Publ., 399, 1-62.

WATANABE, T. K., LEE, W. H., INOUE, Y. AND KAWANISHI, M. 1977. Genetic variation of the hybrid crossability between $D$. melanogaster and D. simulans. Jap. J. Genet., 52, 1-8.

WELBERGEN, PH., VAN DIJKEN, F. R. AND SCHARLOO, W. 1987. Collation of the courtship behaviour of the sympatric species Drosophila melanogaster and Drosophila simulans. Behaviour, 101, 253-274. 